\title{
Low-dose daily oral metronidazole is associated with fewer malignant vesicovaginal and rectovaginal fistulae in locally recurrent cervical cancer Results from a ten-year retrospective cohort
}

Reena George MD, Thotampuri Shanthi Prasoona DMRT, Ramu Kandasamy MPhil, Thenmozhi Mani Ph.D, Shakila Murali BSc, Roja Rekha MBA, Jayaprakash Mulilyil Dr.PH

\section{Christian Medical College, Vellore, India}

\section{OBJECTIVES}

One woman dies with cervical cancer every two minutes. Patients with vesicovaginal and rectovaginal fistulae endure incontinence, indignity and isolation in their final months.

Necrosis within the anterior vaginal wall is a risk factor for fistulae. Metronidazole reduces anaerobic necrosis, discharge and malodor. We aimed to assess if patients who received low dose maintenance metronidazole had a lower risk of vesicovaginal and rectovaginal fistulae.

\section{METHODS}

In this ten-year retrospective cohort study we identified 208 patients with post-treatment residual or recurrent pelvic disease from our palliative care database. 146 patients had been followed up until death.

72 patients developed fistulae before death. There were 49 VVFs, 10 RVFs, and 13 VVF+RVF.

To our knowledge, this is the largest reported series of malignant vesicovaginal and rectovaginal fistulae.

76 patients received oral maintenance metronidazole $200 \mathrm{mg}$ once daily (MM) for 2 to 86 weeks (IQR 4-16 weeks).

\section{FINDINGS AND IMPLICATIONS}

Fewer MM patients developed a fistula before death. (22.4\% vs. $41.7 \%, \mathrm{P}=0.005)$.

The median fistula free survival was significantly longer on MM. (42.9 m vs. $14.1 \mathrm{~m}, \mathrm{P}<0.001)$.

A longer post-recurrence survival was observed in the MM group. (11.5m vs. $8.7 \mathrm{~m}, \mathrm{P}=0.112)$

The survival difference was significant in the subset followed up until death. $(9.7 \mathrm{~m}$ vs. $5.8 \mathrm{~m} . \mathrm{P}=0.001)$ It is hypothesized that malodor, fistulae and debility could have led to neglect by caregivers and poor outcomes.

The impact of maintenance metronidazole, a simple, and inexpensive intervention, on fistulae, malodor, radiotherapy completion and survival needs to be studied in prospective randomized trials

\section{Tab Metronidazole $400 \mathrm{mg}$ tid X 1 week}

Followed by $200 \mathrm{mg}$ once daily to continue

Titrate Metronidazole to SNIFFF severity of smell

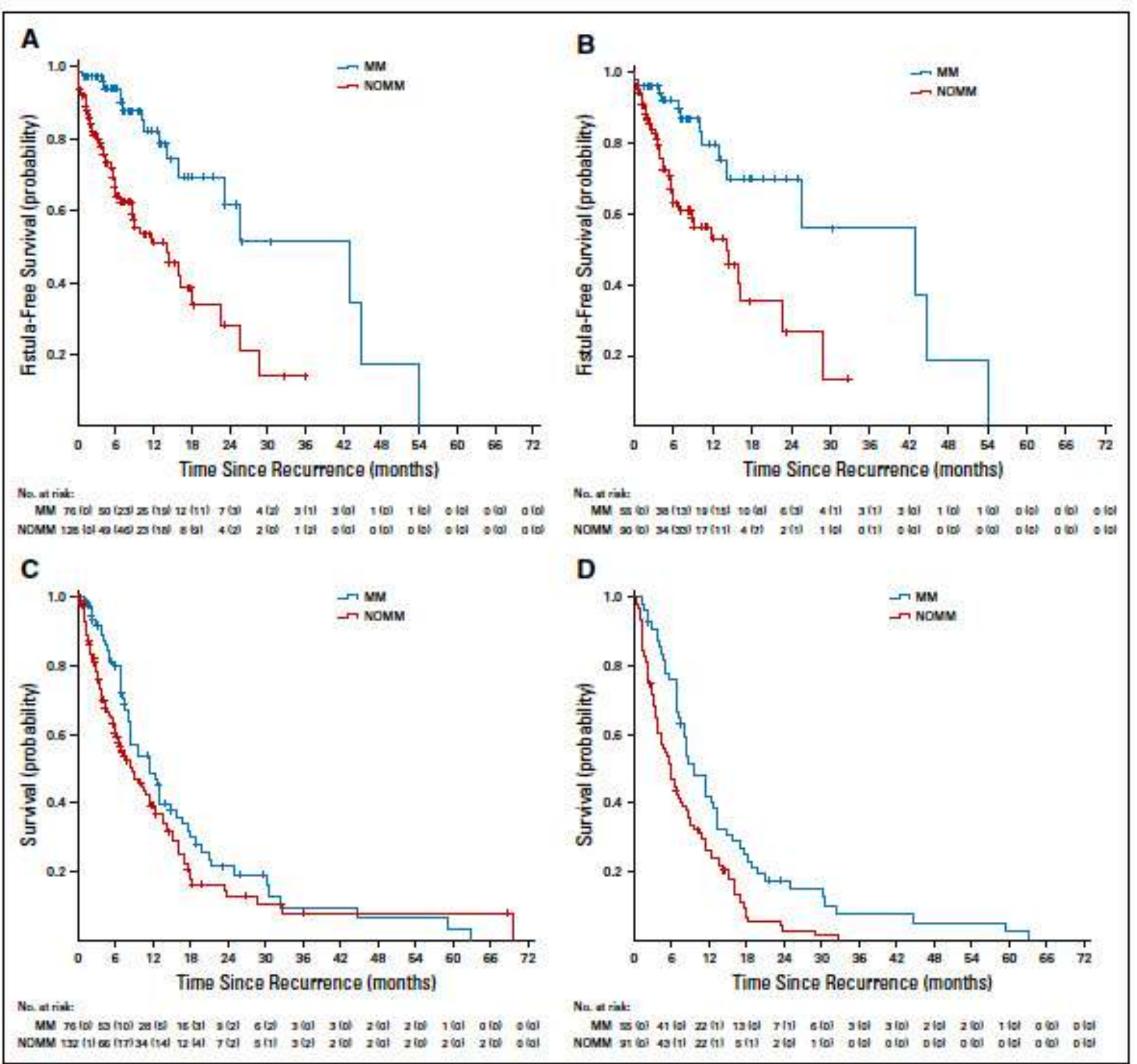

Fl6 3. Kaplan-Meier curves by maintenanoe metronidazole group: (A) fistula-free survival in the primary cohort; (B) fistulafree survival in the subset observed unfil death; (C) postrecurrenoe survival in the primary cohort; and (D) postrecurrenoe survival in the subset observed untildeath. MM, maintenance metronidazole, NOMM, no mainterance metronidazole.

On multivariate analysis, maintenance metronidazole was associated with a lower risk of fistula (HR $0.33,95 \% \mathrm{Cl} 0.16-0.67, \mathrm{P}=0.002$ ) and a lower risk of death (HR 0.56, $95 \% \mathrm{Cl} 0.39-0.81, \mathrm{P} 0.002$ ) in the subset of 146 patients followed up until death.

Published in: Reena George; Thotampuri Shanthi Prasoona; Ramu Kandasamy; Thenmozhi Mani; Shakila Murali; Roja Rekha; Jayaprakash Muliyil; Journal of Global Oncology 2019 51-10.

DOI: 10.1200/JGO.19.00206 J Global Oncol. @ 2019 by American Society of Clinical Oncology Licensed under the Creative Commons Attribution 4.0 License



A Titrating oral metronidazole to the severity of smell: the SNIFFF ladder

B The possible consequences of uncontrolled anaerobic necrosis and smell 